\title{
Seasonal variation in arterial blood pressure
}

\author{
P J BRENNAN，GILLIAN GREENBERG，W E MIALL，S G THOMPSON
}

\begin{abstract}
Blood pressure measurements recorded during the Medical Research Council's treatment trial for mild hypertension have been analysed according to the calendar month in which the readings were made. For each age, sex, and treatment group systolic and diastolic pressures were higher in winter than in summer. The seasonal variation in blood pressure was greater in older than in younger subjects and was highly significantly related to maximum and minimum daily air temperature measurements but not to rainfall.
\end{abstract}

\section{Introduction}

The Medical Research Council's treatment trial for mild hypertension has recruited over 17000 men and women with diastolic (V) blood pressures of 90-109 $\mathrm{mm} \mathrm{Hg}$. Each participant in the trial has his blood pressure measured twice at entry to the trial and at each follow-up visit, and is followed up for five years. The measurements are made by nurses using Hawksley randomzero sphygmomanometers. ${ }^{1}$ The data provided us with an opportunity to analyse the range of seasonal variation in arterial pressure.

\section{Patients and methods}

TRIAL PROCEDURE

Blood pressure measurement-The trial, which is still in progress, is being conducted in 190 centres throughout England, Scotland, and Wales. All but 14 centres are group general practices; all have age/sex registers. Men and women aged 35-64 years were invited to attend for screening, which was carried out by nurses trained and tested in blood pressure recording techniques as described by Rose. ${ }^{2}$ Two consecutive readings were recorded after the subjects had been seated

MRC Epidemiology and Medical Care Unit, Northwick Park

Hospital, Harrow, Middlesex HA1 3UJ

P J BRENNAN, MSC, member of the scientific staff

GILLIAN GREENBERG, BSC, MB, BS, member of the scientific staff

W E MIALL, MD, FRCP, member of the scientific staff

$S$ G THOMPSON, MA, DIPSTAT, member of the scientific staff for 10 minutes. If the mean of these two measurements was $\geqslant 200 \mathrm{~mm}$ $\mathrm{Hg}$ systolic or $\geqslant 90 \mathrm{~mm} \mathrm{Hg}$ diastolic, the person was recalled unless already receiving antihypertensive treatment or known to be ineligible for the trial. Those recalled had a further two consecutive sphygmomanometer readings recorded at least one week later. If the mean of these four measurements of diastolic pressure lay between 90 and $109 \mathrm{~mm} \mathrm{Hg}$, and the mean systolic pressure was below $200 \mathrm{~mm} \mathrm{Hg}$, an appointment was made for the reading to be checked by a doctor using similar techniques. If the blood pressure found at screening was not confirmed as within the trial range the subject was again recalled, and the mean of the doctor's four readings determined eligibility. Of those invited, $75 \%$ attended for screening; $80 \%$ of those eligible entered the study.

Treatment allocation-After a medical examination (history, physical examination, a 12-lead electrocardiogram, blood and urine tests, and measurements of height and weight), participants were allocated at random to groups receiving either a thiazide diuretic (bendrofluazide $5 \mathrm{mg}$ twice daily) or a beta-blocking agent (propranolol, usually up to $120 \mathrm{mg}$ twice daily) or to a group receiving placebo tablets matching these primary regimens. The active drugs are supplemented, if necessary, by methyldopa or guanethidine. The trial is single blind.

Follow-up-Follow-up visits are arranged at fortnightly intervals for the first three months, then at three-monthly intervals to the end of the first year. Thereafter routine visits are at six-monthly intervals, but those with inadequate blood pressure control or other problems are seen more frequently. At each follow-up visit the nurse records two sphygmomanometer readings and calculates their mean value; dose adjustments are carried out in consultation with the doctor. After each year in the study a medical examination similar to that undertaken at entry is repeated; on these occasions the nurse records the blood pressure in the usual way immediately before the medical examination but the patient is aware that the full examination will follow.

Meteorological measurements-Daily measurements of maximum and minimum temperature and of rainfall were provided by the Meteorological Office for the period from January 1977 to November 1981 for three cities, Manchester, Birmingham, and London. In relating blood pressure readings to meteorological measurements data for clinics geographically related to these three cities (fig 1 ) have been considered for the same days: Only those clinics inside the three arbitrarily selected areas marked in fig 1 have been included in these analyses.

\section{Results}

The number of trial participants who entered the study in each calendar month is shown by sex in table I. The trial's screening and entry programmes avoided British holiday seasons and this explains 
the smaller totals in April, August, and December. A higher proportion entered the trial in winter than in summer; a higher proportion of annual re-examinations, therefore, occurred in winter than in summer. Table II shows the number of duplicate blood pressure measurements available for analysis. Entry measurements and those recorded within three months of entry, while pressures were falling rapidly, have been omitted from this table and from the following analyses.

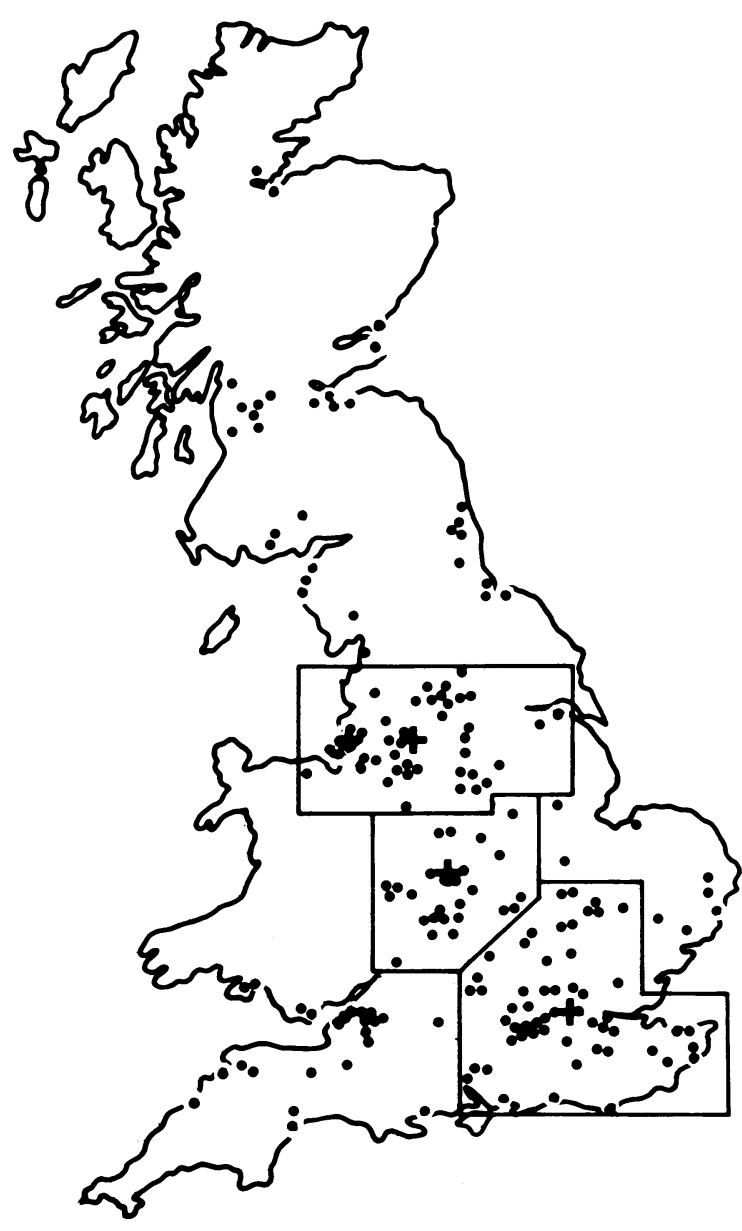

FIG 1-Geographical distribution of MRC treatment trial clinics in relation to three major cities.

Type of examination-Mean blood pressures were higher at annual medical examinations than at the intermediate routine follow-up visits. In fig 2 the data from the measurements shown in table II are shown as mean values of systolic and diastolic pressure for annual examinations and routine follow-up visits separately according to the month in which they were recorded (fig $2 a$ for men and fig $2 \mathrm{~b}$ for women). The data are shown separately for the bendrofluazide, propranolol, and placebo groups. The small but consistent pressor effect of annual medical examinations, affecting systolic pressure more than diastolic pressure and women more than men, was evident in each treatment group. The overall differences between annual and non-annual readings were: in men, $1.5 \mathrm{~mm} \mathrm{Hg}$ in systolic and $0.3 \mathrm{~mm}$ $\mathrm{Hg}$ in diastolic readings, and in women, $3.8 \mathrm{~mm} \mathrm{Hg}$ and $1.1 \mathrm{~mm} \mathrm{Hg}$ respectively; these differences have been subtracted from the figures
TABLE II-Number of duplicate blood pressure measurements recorded by treatment regimen and sex

\begin{tabular}{lccc}
\hline & $\begin{array}{c}\text { Bendrofluazide } \\
\text { group }\end{array}$ & $\begin{array}{c}\text { Propranolol } \\
\text { group }\end{array}$ & $\begin{array}{c}\text { Placebo } \\
\text { group }\end{array}$ \\
\hline Men & 11891 & 12167 & 24444 \\
Women & 11202 & 11256 & 22079 \\
\hline Total & 23093 & 23423 & 46523 \\
\hline
\end{tabular}

for the annual measurements to give the results for seasonal trends presented in figs $3 \mathrm{a}$ and $3 \mathrm{~b}$.

Seasonal trends, treatment group, and age-For each treatment group in both sexes arterial pressures were higher in winter than in summer (figs $3 a$ and $b$ ). These data also suggest that the effects of seasonal factors on blood pressure were greater in older than in younger subjects.

Other factors - The within-person relationship of blood pressure and weight, although apparent in the trial data, was not strong enough to account for more than a very small part of the seasonal trends. Pulse rates showed no consistent seasonal differences in the trial data.

\section{STATISTICAL ANALYSIS}

Analysis of the relationship between blood pressure measurements and meteorological data was carried out as follows. Firstly, the blood pressure measurements made at annual examinations were adjusted to levels recorded at routine follow-up. The deviation on each occasion of each participant's pressure from his or her own mean pressure was then computed. To avoid introducing an obvious seasonal bias in calculating mean pressure, blood pressure data were omitted for any person not contributing the four measurements (at three, six, nine, and 12 months) during the first year and for those not contributing two readings at six-monthly intervals in any subsequent year; $11 \%$ of the measurements were omitted for this reason. The deviation of each person's pressure from his or her mean value was then related to the maximum and minimum air temperatures and to the rainfall on the same day at the nearest of the three cities. The mean number of duplicate blood pressure readings available per person in this analysis was $6 \cdot 0$, and the consequent interdependence of the calculated deviations did not bias the relationships with meteorological data, although the presented $\mathrm{p}$ values are very slightly underestimated.

Regression coefficients of blood pressure deviation on air temperature were computed. Almost all coefficients with either maximum or minimum air temperature were highly significant for each treatment regimen, for each of the three age groups, for both sexes, and for deviations in both systolic and diastolic pressure. All the relationships were negative: the lower the air temperature the higher the pressure.

The relation between rainfall and blood pressure was much weaker and was statistically significant in only four of the 36 computations. For men aged 35-44 years taking propranolol there was a positive correlation of rainfall with systolic $(p<0.01)$ and diastolic $(p<0.05)$ deviations, and for women aged 45-54 years taking placebo the correlations were positive and significant $(p<0.05$ and $p<0.01)$ respectively.

The results of regression analysis are shown in table III, expressed as the mean deviations in systolic and diastolic pressure associated with a $20^{\circ} \mathrm{C}$ change in maximum air temperature (the difference between a hot summer day and a cold winter day in Britain). The coefficients of blood pressure change on minimum air temperature were very similar. Low temperatures were associated with a greater rise in blood pressure in older than in younger subjects in both sexes and in each treatment group. There was no evidence that treatment influenced this relationship.

In men aged 55-64 years mild hypertensives had systolic pressures 6-7 $\mathrm{mm} \mathrm{Hg}$ higher and diastolic pressures 3-4 $\mathrm{mm} \mathrm{Hg}$ higher on a

TABLE I-Number of trial entrants by month of entry and sex

\begin{tabular}{|c|c|c|c|c|c|c|c|c|c|c|c|c|c|}
\hline & Jan & Feb & Mar & Apr & May & Jun & Jul & Aug & Sep & Oct & Nov & Dec & Total \\
\hline $\begin{array}{l}\text { Men } \\
\text { Women }\end{array}$ & $\begin{array}{l}900 \\
790 \\
\end{array}$ & $\begin{array}{l}853 \\
754 \\
\end{array}$ & $\begin{array}{l}898 \\
820\end{array}$ & $\begin{array}{l}644 \\
579 \\
\end{array}$ & $\begin{array}{l}698 \\
719 \\
\end{array}$ & $\begin{array}{l}757 \\
755 \\
\end{array}$ & $\begin{array}{l}724 \\
641 \\
\end{array}$ & $\begin{array}{l}445 \\
373 \\
\end{array}$ & $\begin{array}{r}661 \\
613 \\
\end{array}$ & $\begin{array}{l}893 \\
864 \\
\end{array}$ & $\begin{array}{l}976 \\
875 \\
\end{array}$ & $\begin{array}{l}552 \\
498 \\
\end{array}$ & $\begin{array}{r}9001 \\
8281 \\
\end{array}$ \\
\hline Total & 1690 & 1607 & 1718 & 1223 & 1417 & 1512 & 1365 & 818 & 1274 & 1757 & 1851 & 1050 & 17282 \\
\hline
\end{tabular}



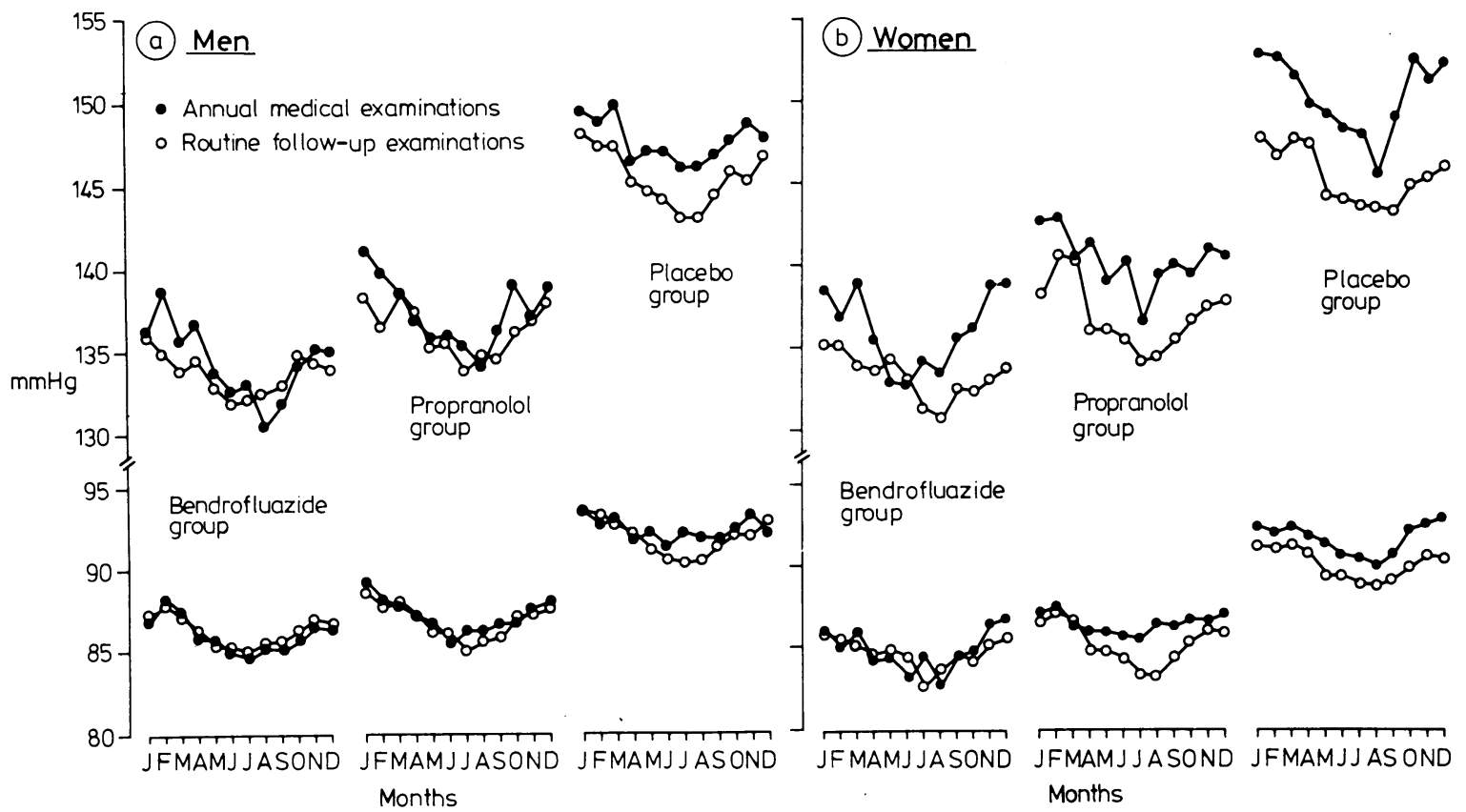

FIG 2-MRC treatment trial for mild hypertension: seasonal trends in blood pressure in (a) men and (b) women by treatment regimen and type of examination.

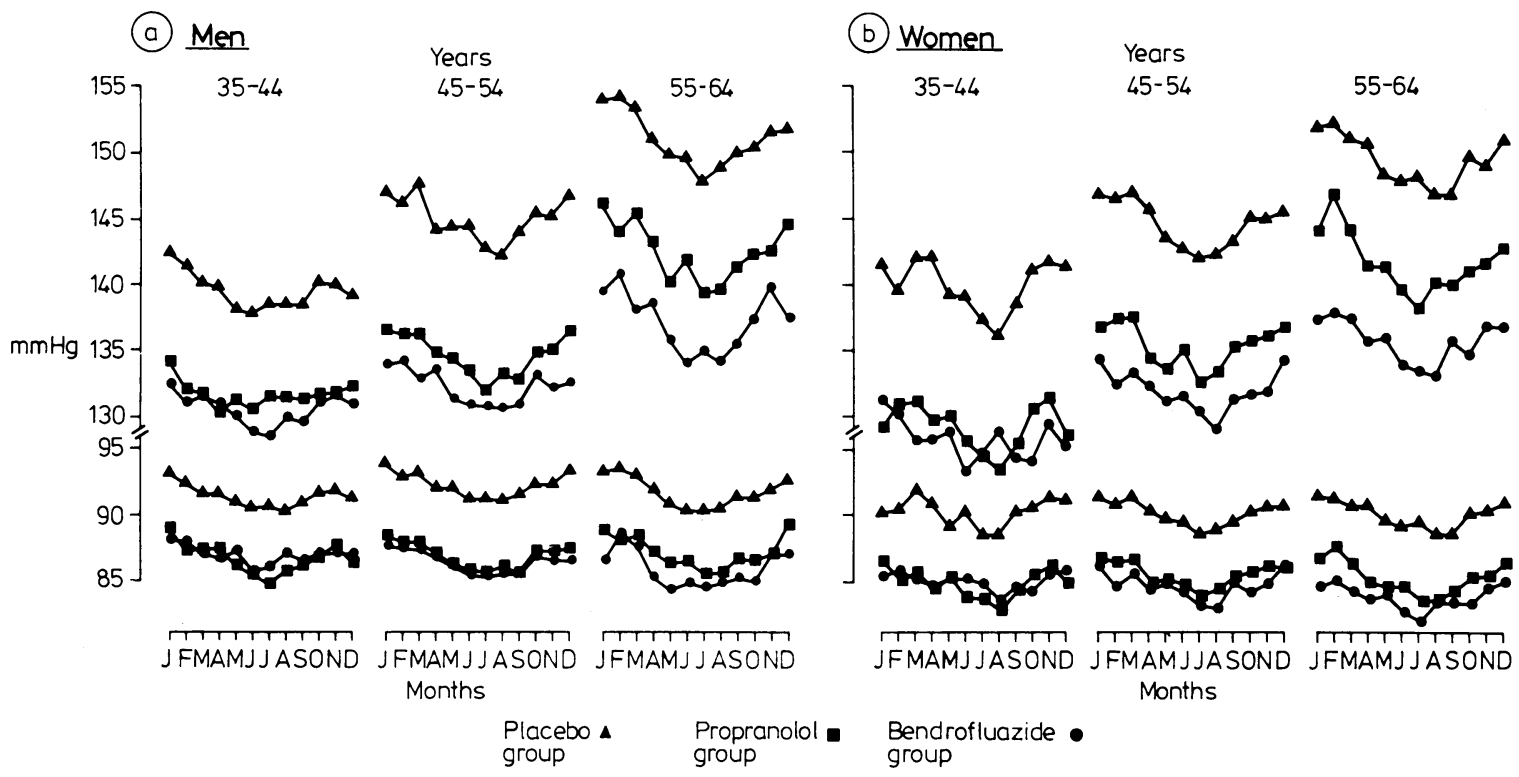

FIG 3-MRC treatment trial for mild hypertension: seasonal trends in blood pressure in (a) men and (b) women by age and treatment regimen.

TABLE III-Mean deviation in blood pressure associated with a $20^{\circ} \mathrm{C}$ difference in maximum daily temperatures by age, sex, and treatment regimen. (All regression coefficients significant at $p<0.001$ except where marked with an asterisk, where $p<0.01$ )

\begin{tabular}{|c|c|c|c|c|c|c|}
\hline & \multicolumn{2}{|c|}{$\begin{array}{c}\text { Bendrofluazide } \\
\text { group }\end{array}$} & \multicolumn{2}{|c|}{$\begin{array}{c}\text { Propranolol } \\
\text { group }\end{array}$} & \multicolumn{2}{|c|}{$\begin{array}{l}\text { Placebo } \\
\text { group }\end{array}$} \\
\hline & $\begin{array}{c}\text { Systolic } \\
\text { (mm Hg) }\end{array}$ & $\begin{array}{r}\text { Diastolic } \\
(\mathrm{mm} \mathrm{Hg})\end{array}$ & $\begin{array}{c}\text { Systolic } \\
(\mathrm{mm} \mathrm{Hg})\end{array}$ & $\begin{array}{r}\text { Diastolic } \\
(\mathrm{mm} \mathrm{Hg})\end{array}$ & $\begin{array}{r}\text { Systolic } \\
(\mathrm{mm} \mathrm{Hg})\end{array}$ & $\begin{array}{r}\text { Diastolic } \\
(\mathrm{mm} \mathrm{Hg})\end{array}$ \\
\hline $\begin{array}{l}\text { Men (age in years): } \\
35-44 \\
45-54 \\
55-64\end{array}$ & $\begin{array}{l}2 \cdot 3 \\
4 \cdot 1 \\
6 \cdot 4\end{array}$ & $\begin{array}{l}1.9 \\
2.8 \\
3.6\end{array}$ & $\begin{array}{l}3 \cdot 0 \\
5 \cdot 0 \\
7 \cdot 3\end{array}$ & $\begin{array}{l}3 \cdot 1 \\
3 \cdot 0 \\
3 \cdot 5\end{array}$ & $\begin{array}{l}3 \cdot 7 \\
4 \cdot 0 \\
6 \cdot 1\end{array}$ & $\begin{array}{l}2 \cdot 1 \\
2 \cdot 6 \\
2 \cdot 8\end{array}$ \\
\hline $\begin{array}{l}\text { Women (age in years): } \\
35-44 \\
45-54 \\
55-64\end{array}$ & $\begin{array}{l}3 \cdot 0^{*} \\
4 \cdot 5 \\
4 \cdot 4\end{array}$ & $\begin{array}{l}2 \cdot 1^{*} \\
2 \cdot 7 \\
2 \cdot 2\end{array}$ & $\begin{array}{l}3.0^{*} \\
5.1 \\
6.9\end{array}$ & $\begin{array}{l}2 \cdot 0^{*} \\
2 \cdot 6 \\
3 \cdot 4\end{array}$ & $\begin{array}{l}4 \cdot 6 \\
5 \cdot 4 \\
6 \cdot 3\end{array}$ & $\begin{array}{l}2 \cdot 1 \\
3 \cdot 1 \\
2 \cdot 9\end{array}$ \\
\hline
\end{tabular}

$* \mathrm{p}<0.01$. 
cold winter day than on a warm summer day; in men aged 35-44 years the comparable figures were $2-4 \mathrm{~mm} \mathrm{Hg}$ systolic and $2-3 \mathrm{~mm} \mathrm{Hg}$ diastolic. The effects of temperature on pressure were similar in women. These are likely to be underestimates of the true effects because the meteorological measurements related to cities up to 100 miles from some of the clinics and because the maximum or minimum temperatures would not have usually coincided in time with the blood pressure measurements.

TABLE IV-Effects on systolic and diastolic blood pressure of a $20^{\circ} \mathrm{C}$ difference in maximum air temperature in persons aged 35 and 65 according to body build

\begin{tabular}{lcc}
\hline Age and body build & $\begin{array}{c}\text { Systolic } \\
\text { difference } \\
(\mathrm{mm} \mathrm{Hg})\end{array}$ & $\begin{array}{c}\text { Diastolic } \\
\text { difference } \\
\text { (mm Hg) }\end{array}$ \\
\hline 35 years: & 2.3 & 2.4 \\
Thin & 1.9 & 1.9 \\
Obese & & 3.5 \\
65 years: & 6.7 & 3.1 \\
Thin & 6.2 & \\
\hline
\end{tabular}

The data from all age, sex, and treatment groups were then pooled in stepwise multiple regression analyses undertaken to determine the influence (on the deviations of blood pressure from its mean value for each individual as described above) of maximum air temperature minimum air temperature, and daily rainfall. Maximum temperature entered the regression first (with $\mathrm{p}<0.00001$ for both systolic and diastolic deviations), and neither minimum temperature nor rainfall made a significant contribution after this. The effects of age, sex mean blood pressure, allocated treatment regimen, and body build (expressed in terms of Quetelet's index-that is, weight divided by height $^{2}$ ) on this relationship with maximum temperature were also investigated. For systolic deviations there were significant interactions of the maximum temperature effect only with age $(p<0.00001)$ and Quetelet's index $(\mathrm{p} \simeq 0.04)$, after which neither sex, blood pressure, nor treatment regimen contributed significantly. For diastolic deviations the significant interactions were, in order, with Quetelet's index $(p \simeq 0.001)$ and with age $(p \simeq 0.002)$. The multiple correlation coefficients were $0 \cdot 15$ and 0.13 respectively. The increase in both systolic and diastolic pressures due to cold was greater in older than younger subjects and less in obese than thin subjects. Examples of the magnitude of these influences are shown in table IV, where the estimated effect on blood pressure of a $20^{\circ} \mathrm{C}$ change in maximum air temperature is shown for thin (Quetelet's index 19) and obese (Quetelet's index 35) people aged 35 and 65 years. The selected values for Quetelet's index are those for subjects two standard deviations below and above the trial mean. The relationship with body build, though statistically significant, was small and clearly of no clinical significance but might provide a clue to the mechanisms involved. An inspection of the residuals from this regression (that is, the variation in blood pressure deviations not explained by this regression) by month of measurement still showed some seasonal pattern, being on average highest in March and lowest in July for both systolic and diastolic pressures, a difference between the two months of $1.0 \mathrm{~mm} \mathrm{Hg}$ for systolic and $0.5 \mathrm{~mm} \mathrm{Hg}$ for diastolic. The raw data of blood pressure deviations showed a maximum difference between any two months of, on average, $4.9 \mathrm{~mm} \mathrm{Hg}$ for systolic and $2.9 \mathrm{~mm} \mathrm{Hg}$ for diastolic. So a large proportion of the mean seasonal variation in blood pressure could be accounted for by the relationships with daily air temperature. It is possible, however, that the relationships were not causal and that the seasonal variation in blood pressure was related to factors other than temperature which change with season. The effect of air temperature on blood pressure over a shorter period of time may not be the same as the effects for changes from season to season.

\section{Discussion}

A seasonal influence on blood pressure was first described in Britain by Rose, ${ }^{3}$ who analysed measurements in 56 men observed for 1-3 years at a clinic for ischaemic heart disease. In broad outline his findings resembled those described above; his peak blood pressure values, however, occurred in spring rather than in the winter and his lowest values were obtained in September rather than in July. These discrepancies might result from climatic differences between the years covered by the two studies.

Heller et $a l^{4}$ reported an inverse relationship between diastolic pressure and the temperature of the room in which measurements were made in the UK Heart Disease Prevention Project and found that standardisation for room temperature largely removed the seasonal effect. In a recent study from Japan Hata $e \mathrm{al}^{5}$ reported similar seasonal variation in arterial pressure in small groups of borderline and established cases of essential hypertension but not in normotensive subjects. They also found in the hypertensive patients that mean plasma noradrenaline concentrations were significantly higher in winter than in summer. No comparable differences were found in either plasma renin activity or plasma aldosterone concentrations. In all three groups urinary excretion of catecholamines and sodium was significantly higher in winter than in summer, but the seasonal differences in blood pressure did not correlate with the seasonal differences in either plasma noradrenaline concentrations or the urinary excretion of sodium or catecholamines. Nevertheless, Hata and his colleagues attributed the increase in winter blood pressure to increased sympathetic nervous activity in cold weather.

The present MRC trial data indicate that the pressor effect associated with cold outdoor temperatures was greater in older and thinner people than in younger and more obese ones and that little residual seasonal variation remained after these effects of air temperature had been allowed for. Room temperatures were not recorded in the trial clinics, but most of the measurements were made in comfortably warm rooms and after the participants had been inside the practice premises for about 10 minutes. In many people the skin temperature on a cold day would have risen during this time, though the rise may have occurred more slowly in older subjects; to what extent the effect of outdoor temperature on blood pressure is mediated through skin temperature, body temperature, or other mechanisms cannot be determined from these data.

The higher winter mortality from ischaemic heart disease and from stroke is well known. ${ }^{6}$ In England and Wales mortality from ischaemic heart disease shows a winter peak which averages about $50 \%$ higher than that occurring in the summer trough but varies from about $20 \%$ to $70 \%$ depending on the weather. Rose ${ }^{7}$ showed that the excess December mortality from ischaemic heart disease over that occurring in the corresponding June, during a period of 13 years, correlated with an air temperature index to the extent of -0.95 for men and -0.88 for women; this time-distribution of high and low levels of mortality corresponds closely with those for blood pressure in the present study. The high correlation with temperature suggests a causal relationship; the correlation with air pollution and rainfall were much weaker.

Daily death rates from myocardial infarction and from stroke show similar relationships with minimum air temperature in England and Wales and in New York. ${ }^{8} \mathrm{~A}$ linear trend of mortality rates, high in cold weather and low in warm weather, is found between $-10^{\circ} \mathrm{C}$ and $+20^{\circ} \mathrm{C}$. Temperatures outside this range are associated with considerably higher mortality in New York. The slope of the regressions of death rates on temperature in those over 60 years is steeper than in those under 60 years and steeper in Britain than in New York. Central heating is less common in Britain.

There is little evidence that other risk factors for cardiovascular disease show seasonal differences of a magnitude which would contribute to the high cardiovascular mortality in winter. People probably take less exercise and smokers may smoke more in winter than in summer; energy requirements increase and this increases the sodium load and hence the sodium excretion rate in winter. Biochemical risk factors show no relationship to minimum air temperature ${ }^{9}$; there is some evidence that certain haemostatic variables (factor VII, antithrombin III, and fibrinolytic activity) show temperature effects but the pattern is inconsistent and to some extent paradoxical in this context. ${ }^{9}$ 
The seasonal effect may be an acute response to ambient temperature, perhaps initiated by a sympathetic reflex initiated by skin cooling. This would accord with the known responses to the "cold pressor test," which increase with age. It is perhaps surprising that the effect seems largely uninfluenced by treatment, especially with a beta-blocker, but the dose used in the trial is not enough to abolish sympathetic activity.

These data provide further evidence that environmental temperatures affect arterial pressure in middle-aged men and women with mild hypertension. The influence of seasonal factors on the blood pressures of normotensive or severely hypertensive subjects or on the blood pressures of the elderly may differ. When the full trial results are available it may be possible to estimate the effect of seasonally related blood pressure increase on cardiovascular morbidity and mortality in the middle-aged mild hypertensives who make up the trial population. It would, however, be unwise to extrapolate from these results for this selected group and attempt this estimation for other populations.

We thank the MRC Working Party on mild/moderate hypertension (whose members include: Professor W S Peart, chairman; Mrs G R Barnes; Mr P Broughton; Professor C T Dollery; Dr K G Green; Dr G Greenberg; Dr M F Hudson; Dr A F Lever; Dr T $\mathbb{W}$ Meade; Professor G A Rose; and $\mathrm{Dr} W \mathrm{E}$ Miall, secretary) for permission to publish these data while the trial is still in progress, and the nurses and doctors participating in the study who made all the blood pressure measurements. Meteorological data were kindly provided by the Meteorological Office, Bracknell. Thanks are also due to Imperial Chemical Industries Ltd (for generous financial support and for tablets of propranolol and its placebo); to Glaxo Operations UK Ltd (for tablets of bendrofluazide and its placebo); to Merck Sharp \&
Dohme Ltd (for providing a mobile screening unit and its running expenses and for supplies of methyldopa); and to Ciba Laboratories (for supplies of guanethidine).

Requests for reprints should be addressed to Mr P J Brennan, MRC Epidemiology \& Medical Care Unit, Northwick Park Hospital, Watford Road, Harrow, Middx HA1 3UJ.

\section{References}

1 Wright BM, Dore CF. A random-zero sphygmomanometer. Lancet 1970 ; : $: 337-8$.

${ }^{2}$ Rose G. Standardisation of observers in blood pressure measurement. Lancet 1965 ; : $: 673-4$.

${ }^{3}$ Rose G. Seasonal variation in blood pressure in man. Nature $1961 ; 189$ : 235.

4 Heller RF, Rose G, Tunstall-Pedoe HD, Christie DGS. Blood pressure measurement in the United Kingdom Heart Disease Prevention Project. $\mathcal{F}$ Epidemiol Community Health 1978;32:235-8.

${ }^{5}$ Hata T, Ogihara T, Maruyama A, et al. The seasonal variation of blood pressure in patients with essential hypertension. Clinical and Experimental Hypertension-Theory and Practice 1982;A4:341-54.

${ }^{6}$ Bull GM. Meteorological correlates with myocardial and cerebral infarction and respiratory disease. British fournal of Preventive and Social Medicine 1973;27:108-13.

${ }^{7}$ Rose G. Cold weather and ischaemic heart disease. British fournal of Preventive and Social Medicine 1966;20:97-100.

${ }^{8}$ Bull GM, Morton J. Environment, temperature and death rates. Age Ageing 1978;7:210-24.

9 Bull GM, Brozovic M, Chakrabarti R, et al. Relationship of air temperature to various chemical, haematological and haemostatic variables. f Clin Pathol 1979;32:16-20.

(Accepted 22 fune 1982)

\title{
Fungal arthritis simulating juvenile rheumatoid arthritis
}

\author{
J HAAPASAARI, R V ESSEN, A KAHANPÄÄ, ANJA A I KOSTIALA, K HOLMBERG, J AHLQVIST
}

\begin{abstract}
Petriellidium boydii is often isolated from maduromycosis but has recently been associated with arthritis. $A$ previously healthy 6-year-old boy developed chronic purulent arthritis of the knee after a bicycle accident. Culture of aspirate grew no pathogens and antibiotic treatment had no effect. Culture of synovial fluid grew $P$ boydii, which responded initially to amphotericin but reappeared after six months. Subsequent treatment with miconazole was stopped after development of haema-
\end{abstract}

Rheumatism Foundation Hospital, SF-18120 Heinola 12, Finland

J HAAPASAARI, MB, paediatrician

R V ESSEN, MB, laboratory physician-in-chief

Department of Bacteriology and Immunology, University of Helsinki, SF-00290 Helsinki 29

A KAHANPÄ $\ddot{A}, M D$, docent of clinical mycology

ANJA A I KOSTIALA, MD, docent of clinical immunology

Section of Mycology, National Bacteriological Laboratory, S-10521 Stockholm

K HOLMBERG, MD, professor

Department of Pathology, Aurora Hospital, SF-00250 Helsinki 25 J AHLQVIST, MD, head turia. The fungus was sensitive to ketoconazole, and treatment with this drug cured the infection.

With the introduction of ketoconazole it is of practical importance to recognise fungal infections.

\section{Introduction}

Petriellidium boydii (perfect form: Allescheria boydii, imperfect form: Monosporium apiospermum) is best known for causing Madura foot, but lately various other associations, particularly with arthritis, ${ }^{1-3}$ have been reported from America. We believe our case to be the first from Europe.

\section{Case report}

A previously healthy 6-year-old boy injured his right knee in a bicycle accident in August 1978. The wound was cleaned and sutured without delay. Ten days later the knee became swollen and $25 \mathrm{ml}$ turbid fluid was aspirated. One week later the knee was again swollen, red, and tender, and the patient was feverish. Twenty-five ml turbid fluid was aspirated and sent for bacterial culture, which proved negative. As the patient also had raised erythrocyte sedimentation rate and C-reactive protein concentration he was admitted to hospital and treated for bacterial arthritis with various systemic and intra-articular antibiotics, but without clinical improvement. Histological examination of synovial biopsy specimens showed purulent arthritis, but repeated bacterial cultures remained negative. He was therefore sent for rheumatological evaluation in November 1978. 